IP Periodica Polytechnica Civil Engineering

\author{
60(3), pp. 397,404, 2016 \\ DOI: $10.3311 /$ PPci.7853 \\ Creative Commons Attribution (1) \\ RESEARCH ARTICLE
}

\section{Rheological Evaluation of Ageing Properties of SEBS Polymer Modified Bitumens}

\author{
Djaffar Si Bachir, Samy Dekhli, Khedidja Ait Mokhtar
}

Received 04-12-2014, revised 21-08-2015, accepted 23-09-2015

\begin{abstract}
Ageing of bitumen is an important cause of reduced durability of asphalt pavements. Therefore, the polymer modified bitumens are recommended to increase the durability of the material. In the present work, rheology has been applied to evaluate the properties of Styrene-Ethylene-Butadiene-Styrene (SEBS) polymer modified bitumen (PMB) to compare to the 35/50 penetration grade bitumen, before and after ageing. The effects of ageing on the physical and rheological properties of (PMB) were evaluated using SARA analysis, penetration test, softening point test and dynamic shear rheometer test (DSR). The binders were aged by Rolling Thin Film Over Test (RTFOT) and Pressure Ageing Vessel (PAV). The results showed that use of SEBS polymer reduces the ageing effect on physical and rheological properties of the bitumen binder as illustrated through lower ageing index of complex modulus and an increase in tang $\delta$ indicating that the SEBS polymer improve the ageing resistance of bitumen binder.
\end{abstract}

\section{Keywords \\ polymer $\cdot$ bitumen $\cdot$ ageing $\cdot S E B S \cdot$ rheological $\cdot D S R$}

\section{Djaffar Si Bachir}

Department of Geotechnical and Hydraulic Faculty of Civil Engineering, University of Sciences and Techology Houari Boumediene, BP 32 El Alia Bab Ezzouar Algiers, Algeria

e-mail: dsibachir@yahoo.fr

\section{Samy Dekhli}

Department of Geotechnical and Hydraulic Faculty of Civil Engineering, University of Sciences and Techology Houari Boumediene, BP 32 El Alia Bab Ezzouar Algiers, Algeria

e-mail: dekhli.samy@yahoo.fr

\section{Khedidja Ait Mokhtar}

Department of Geotechnical and Hydraulic Faculty of Civil Engineering, University of Sciences and Techology Houari Boumediene, BP 32 El Alia Bab Ezzouar Algiers, Algeria

e-mail:kaitmokhtar@yahoo.fr

\section{Introduction}

The ageing of bitumen usually results in hardening of bitumen and embrittlement, both in application and in service, which is an important cause of reduced durability of asphalt pavements. In road applications, bitumens are exposed to ageing processes during storage, mixing, transport and laying, as well as in service life. Usually, rapid ageing occurs at high temperatures on the surface of aggregates during manufacture of the asphalt mix. In bitumen ageing, two types of mechanisms are involved. The main ageing mechanism is an irreversible one, characterized by chemical changes of bitumen, which in turn has an impact on the rheological properties. The processes contributing to this type of ageing include oxidation, loss of volatile components and exudation [1]. The second mechanism is a reversible process called physical hardening, which may be attributed to molecular structuring [1]. The rheological and chemical changes associated with laboratory short term and long-term ageing are well known and understood for bitumen. However, the changes associated with ageing are not fully understood for polymer-modified bitumen. There is, therefore, a need to determine the suitability of various testing methods for describing the changes in the rheological performance of modified bitumens, after short term and long-term ageing, and to characterize these changes by providing an explanation of ageing process. To simulate the age hardening occurring during plant mixing and laydown the most utilized test is Rolling Thin Film Over Test (RTFOT) and to simulate long term ageing during service the Pressure Ageing Vessel test (PAV) was adopted in SHRP binder specifications.

The main objective of this paper is to evaluate the effect of ageing on the physical, chemical and rheological properties of Styrene-Ethylene-Butadiene-Styrene (SEBS) polymer modified bitumens by means of conventional binder tests, chemical property tests and dynamic shear rheometer (DSR).

\section{Materials and experimental}

\subsection{Materials}

The conventional bitumen $35 / 50$ penetration grade is commonly used in Algeria. It is provides by the Algerian Oil Refining Company "NAFTAL. The results of penetration grade trials 
and R\&B softening temperature tests, according to ASTM D5 and D36, respectively, as well as chemical composition in terms of SARAs fractions are presented in Table 1 and 2.

Tab. 1. Conventional physical properties of the base bitumen

\begin{tabular}{cccc}
\hline Bitumen & Pen at $25^{\circ} \mathrm{C}$ & Soft.point $\left({ }^{\circ} \mathrm{C}\right)$ & $(\mathrm{PI})$ \\
\hline $35 / 50$ & 41 & 52 & -1.16
\end{tabular}

Tab. 2. SARA analysis of the base bitumen

\begin{tabular}{cccccc}
\hline Bitumen & $\mathrm{S} \mathrm{( \% )^{a }}$ & $\mathrm{A} \mathrm{( \% )}$ & $\mathrm{R} \mathrm{( \% )}^{a}$ & $\mathrm{As} \mathrm{( \% )}$ & $\mathrm{Cl}^{b}$ \\
\hline $35 / 50$ & 8.7 & 36.4 & 44.6 & 10.3 & 0.234 \\
\hline
\end{tabular}

$S \quad$ Saturates,

A Aromatics,

$R \quad$ Resins,

As Asphaltenes,

a Iatroscan thin film chromatography SARA analysis.

${ }^{b}$ CI Colloidal index.

The thermoplastic polymer used as modifier is SEBS (Kraton G1652). The main characteristics of SEBS polymer as given by the manufacturers are reported in Table 3

Tab. 3. Main physical and chemical characteristics of SEBS Polymer

\begin{tabular}{cc}
\hline Properties & Values \\
\hline Physical aspect & Porous \\
Molecular structure type Polystyrene (wt.\%) & Linear \\
Polystyrene content (wt) & $30 \%$ \\
Density (ASTM D792) & $0.91 \mathrm{gr} / \mathrm{cc}$ \\
Styrene/Rubber ratio & $30 / 70$ \\
Tensile strength (ASTM D412) & $4500 \mathrm{psi}$ \\
Elongation at break (ASTM D412) & $500 \%$ \\
Hardness shore (A) (ASTM D2240) & 69 \\
Melt flow index (ASTM D1238) & $5 \mathrm{~g} / 10 \mathrm{~min}$ \\
Processing temperature & $280^{\circ} \mathrm{C}$ \\
\hline
\end{tabular}

\subsection{Preparation of SEBS modified bitumens}

The modified binders were prepared at $180^{\circ} \mathrm{C}$ and a speed of $600 \mathrm{rpm}$ using a high shear mixer. While preparing SEBS modified binders, $600 \mathrm{~g}$ of the bitumen was melted and poured into a $2000 \mathrm{ml}$ spherical flask. Upon reaching $175^{\circ} \mathrm{C}$, the powdered SEBS polymer was added to the bitumen. After reaching $180^{\circ} \mathrm{C}$, the mixing was continued at the temperature for two hours. The mixer speed was maintained through the mixing process. After completion, the SEBS-bitumen was removed from the flask and divided into small containers. The blend was cooled to room temperature, sealed with aluminum foil and stored for further testing. The SEBS concentrations in the base bitumen is $5 \%$ by weight. The uniformity of dispersion in the base bitumen was confirmed by passing the mixture through an ASTM 100\# sieve. After completion, the different samples were cooled to room temperature, covered with aluminum foil and stored for testing.
The choice of $5 \%$ SEBS addition to the PMB mix was justified by the softening point test results on SEBS PMBs taken from the top and bottom of the tube in the storage stability test [2] indicate that, the SEBS PMBs are not likely to be affected by storage with polymer content less than $7 \%$ of SEBS.

When the content of SEBS is 3 and $5 \mathrm{wt} . \%$, the temperature difference is less than $2.2^{\circ} \mathrm{C}$, which shows that SEBS modified bitumen are stable at high temperature according to the pavement modified bitumen standard. This gives a better behavior at high temperatures in terms of permanent deformation, and positively affects the storage stability. On the contrary, for the bitumen samples modified with $7 \%$ of SEBS polymer, the difference in the softening points was large, which imply that the phase separation of the SEBS/bitumen mixture was serious, and the polymer-modified bitumen can be considered to be unstable.

The results suggest that the SEBS content of 5\% is probably the upper limit below which fairly good storage stability can be achieved.

\subsection{Ageing experiment}

Ageing of bitumen is induced by chemical and physical changes that occur during the production of the pavement and throughout its service life. The process is usually accompanied by hardening of the binder, which general influences the deterioration of the asphalt pavement.

In order to determine the influence of ageing on the rheological properties of PMBs, the short and long term laboratory ageing of the base and SEBS polymer modified bitumens were performed using the Rolling Thin Film Over Test (RTFOT, ASTM D 2872) and the Pressure Ageing Vessel (PAV, AASHTO PPI), respectively.

The standard ageing procedures of $163^{\circ} \mathrm{C}$ for and $75 \mathrm{~min}$ for the RTFOT and $100^{\circ} \mathrm{C}, 2.1 \mathrm{MPa}$ and 20 hours for the PAV were used. The aged binders were evaluated by measuring their rheological properties and chemical composition.

\subsection{Conventional binder tests}

The base and the polymer modified bitumens aged were subjected to the following conventional binder tests: penetration $\left(25^{\circ} \mathrm{C}, \mathrm{ASTM}\right.$ D5), softening point temperature (ASTM D36).

In addition, the temperature susceptibility of the modified bitumen samples was calculated in terms of penetration index (PI) using the results obtained from both penetration and softening point temperature tests. A classical approach related to PI calculation has been given in the Shell Bitumen Handbook [3].

$$
P I=\frac{1952-500 \times \log \left(P_{e n} n_{25}\right)-20 \times T B A}{50 \times \log \left(\text { Pen }_{25}\right)-T B A-120}
$$

\subsection{Dynamic Shear Rheometer Test (DSR)}

Dynamic mechanical analysis (DMA) was performed on the base bitumen and SEBS modified bitumen, to determine their rheological properties using dynamic shear rheometer (DSR). 
The dynamic shear rheometer (DSR) was adopted to characterize the viscoelastic behavior of bitumens binders at low and intermediate to high service temperatures. The DSR provides an indication of the rutting resistance of bitumen immediately following construction. Resistance to rutting at high service temperatures in the early stages of pavement life is also evaluated [4. 5].

The principal rheological parameters obtained from DSR were complex shear modulus $\left(\mathrm{G}^{*}\right)$, shear storage modulus $\left(\mathrm{G}^{\prime}\right)$, shear loss modulus (G”) and phase angle $(\delta)$. $\mathrm{G}^{*}$ is defined as the ratio of maximum shear stress to maximum strain and provides a measure of the total resistance to deformation when the bitumen is subjected to shear loading [6]. The phase angle is the phase shift between the applied shear stress and shear strain response during a test and is a measure of the viscoelastic balance of the material behavior. The in-phase and out -of-phase of $\mathrm{G}^{*}$ are defined as the storage modulus G' and the loss modulus G', respectively. The test method requires that a thin bitumen specimen be sandwiched between two parallel metal plates held in a constant temperature medium.

The tests were undertaken with parallel plates testing geometry. The researches involved with the SHRP project have suggested a diameter of plates of $25 \mathrm{~mm}$ with $1 \mathrm{~mm}$ gap for the tests carried out at temperatures above ambient temperature.

The durability of asphalt pavement is greatly influenced by the environmental changes during the year. In the southern Algerian, the air temperature can reach $50^{\circ} \mathrm{C}$ which resulting it into the bitumen by a temperature near to $75^{\circ} \mathrm{C}$.

The DSR tests reported in this paper were performed under controlled-strain loading conditions using frequency sweeps between 0.01 and $10 \mathrm{~Hz}$ at temperatures between $20^{\circ} \mathrm{C}$ and $80^{\circ} \mathrm{C}$.

For specification purposes, the frequency is 10 radians per second which has been related to a traffic speed of $100 \mathrm{~km} / \mathrm{h}$.

\section{Results and discussion}

\subsection{Chemical characterization of the effect of ageing}

The most important changes that cause hardening of the binder in pavements are the changes in the composition of the bitumen molecules from reaction with oxygen, molecular growth (forming of asphaltenes) and molecular structuring that produces different rheological behavior [7, 8].

One method that used to study the changes associated with ageing of paving grade bitumen is to determine the generic composition of the aged bitumen. The changes in the percentages of the Saturates, Aromatics, Resins and Asphaltenes (SARA), obtained from Iatroscan thin layer chromatography, of the base bitumen and PMBs after RTFOT and PAV ageing are shown in Table 4. This table also reports the values of the colloidal instability index (CI), which is defined by $\mathrm{CI}=($ asphaltenes + saturates $) /($ resins + aromatics $)[6]$.

The CI were calculated in order to determine the potential compatibility of the base bitumens to polymer modification.
The analysis of the chemical composition of the base bitumen and the polymer modified samples indicates a similar decrease in aromatics with an increase in asphaltenes and resins with the percentage mass of saturates remaining fairly constant after ageing. The base bitumen and PMB, therefore, showed the expected changes in their chemical composition due to the ageing process caused by RTFOT and PAV ageing.

The SARA data also indicates that the magnitude of increase in asphaltenes and resins and decrease in aromatics after ageing is greater in the presence of polymer in the bituminous matrix. This is explained by the shifting of lower molecular weight fractions towards higher molecular weight fractions (oils towards resins and resins towards asphaltenes) [1].

The changes in chemical composition of the base bitumen and the polymer modified samples are more important after PAV ageing compared to that after RTFOT ageing. This is understandable due to the severe oxidative ageing that occurs during PAV ageing.

In general, a CI higher than 0.28 predicts compatibility problems (phase separation) between the bitumen and the polymer [6]. The data indicate that the CI values of the SEBS PMB are below 0.28 before ageing.

These results can be related to the good compatibility between the bituminous matrix and the SEBS polymer. Moreover, the CI values obtained after ageing are higher than 0.28 resulting in the changes in chemical composition of the base bitumen and the polymer modified samples.

\subsection{Influence of ageing on the conventional properties of the PMB}

The effect of ageing on the penetration and softening point of base bitumen and the SEBS PMB can be seen in Table 5. The ageing of bitumen is commonly evaluated by means of an ageing index, which is defined as the ratio of physical or rheological parameter of the aged bitumen to that of the original bitumen [9]. The results indicate a decrease in penetration and an increase in softening point for base bitumen and PMB after ageing. This indicates a hardening of the binders and corresponds to the oxidative processes identified by SARA analysis.

Temperature susceptibility of PMB is evaluated by the determination of the penetration index (PI), which is defined as the change in the consistency parameter as a function of temperature [10. 11]. Higher penetration index (PI) indicates less temperature susceptibility and more rubbery elastic behavior.

From Table 5, it is observed that the SEBS polymer modified binder significantly reduces the temperature susceptibility of the base bitumen before and after ageing. This clearly shows that polymer modification induces a rubbery elastic behavior conferring to the bitumen better resistance to low temperature cracking and permanent deformation [10].

However, the increased penetration index (PI) observed for the modified sample after PAV ageing, is less important after RTFOT ageing. 
Tab. 4. Changes in chemical composition due to ageing for base bitumen and SEBS PMB

\begin{tabular}{ccccccc}
\hline Binder & Condition & $\mathrm{S}(\%)$ & $\mathrm{A}(\%)$ & $\mathrm{R}(\%)$ & $\mathrm{As}(\%)$ & $\mathrm{Cl}$ \\
\hline \multirow{2}{*}{ Base bitumen } & Unaged & 8.7 & 36.4 & 44.6 & 10.3 & 0.234 \\
& RTFOT & 8.2 & 27.4 & 47.9 & 16.5 & 0.321 \\
& PAV & 6.8 & 24.2 & 50.1 & 18.9 & 0.345 \\
\hline 5\% SEBS & Unaged & 9.1 & 42.7 & 36.1 & 12.1 & 0.269 \\
modified & RTFOT & 8.9 & 40.5 & 37.2 & 13.4 & 0.287 \\
bitumen & PAV & 7.1 & 34.2 & 42.2 & 16.5 & 0.309 \\
\hline
\end{tabular}

Tab. 5. Changes in conventional test data due to ageing for base bitumen and SEBS PMB

\begin{tabular}{ccccc}
\hline Binder & Property & Unaged & RTFOT & PAV \\
& Pen at $25^{\circ} \mathrm{C}$ & 41 & 25 & 13.5 \\
Base bitumen & Soft.point $\left({ }^{\circ} \mathrm{C}\right)$ & 52 & 57 & 63.4 \\
& Pen.Index $(\mathrm{PI})$ & -1.16 & -1.06 & -0.94 \\
\hline $5 \%$ SEBS & Pen at $25^{\circ} \mathrm{C}$ & 15 & 14 & 6.3 \\
modified & Soft.point $\left({ }^{\circ} \mathrm{C}\right)$ & 70.4 & 75.3 & 81.3 \\
bitumen & Pen.Index $(\mathrm{PI})$ & 0.33 & 0.92 & 0.46 \\
\hline
\end{tabular}

The ageing indices for the penetration tests presented in Table 5 show the same trends as seen for the unmodified base bitumen indicating the effect of ageing on the physical characteristics of both the base bitumen and the SEBS PMB are the same.

From Table 6 the ageing index for the RTFOT and PAV aged bitumens indicate that the changes in the traditional, empirical tests are greater after PAV ageing compared to those after RTFOT ageing. However, the relative magnitude of the ageing indices indicate that the effect of ageing on the physical performance of SEBS PMB is less important from that found for unmodified base bitumen.

Tab. 6. Ageing index

\begin{tabular}{cccc}
\hline \multirow{2}{*}{ Binder } & \multirow{2}{*}{ Property } & \multicolumn{2}{c}{ Ageing index } \\
\cline { 3 - 4 } & & RTFOT & PAV \\
\cline { 3 - 4 } & Unaged & Unaged \\
\hline \multirow{2}{*}{ Base bitumen } & Pen at $25^{\circ} \mathrm{C}$ & 0.61 & 0.33 \\
& Soft.point $\left({ }^{\circ} \mathrm{C}\right)$ & 1.09 & 1.22 \\
\hline $5 \%$ SEBS modified & Pen at $25^{\circ} \mathrm{C}$ & 0.93 & 0.42 \\
bitumen & Soft.point $\left({ }^{\circ} \mathrm{C}\right)$ & 1.07 & 1.15 \\
\hline
\end{tabular}

3.3 Influence of ageing on the rheological properties of the PMB

\subsubsection{Dynamic viscoelastic parameters}

In this study, DMA was employed to characterize the rheology of the base bitumen and the modified binder containing 5\% of SEBS before and after standard laboratory ageing (RTFOT and PAV). The most frequent graphical representation used to characterize residue rheological behavior is the complex modulus $\mathrm{G}^{*}$ and the phase angle $\delta$.

The main curve of the complex modulus for base bitumen and modified bitumen, against temperature was obtained, as illustrated in figures $1 \mathrm{a}$ and $1 \mathrm{~b}$.

The isochronal plots for base bitumen and modified bitumen are shown in figures $1 \mathrm{a}$ and $1 \mathrm{p}$ respectively. There is a con-

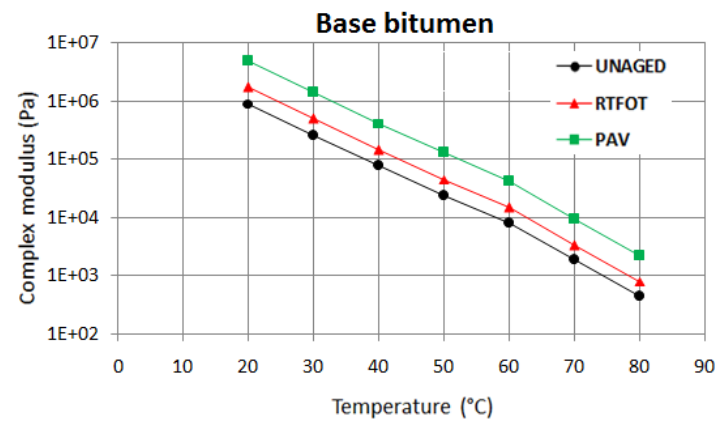

(a)

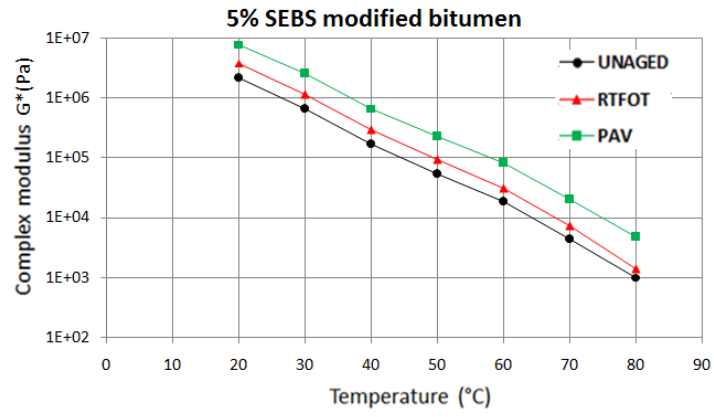

(b)

Fig. 1. Complex modulus as function of temperature at $10 \mathrm{rad} \mathrm{s}^{-1}$ for: (a) Base bitumen, (b) $5 \%$ modified bitumen before and after ageing.

stant increase in complex modulus, $\left(\mathrm{G}^{*}\right)$, over the temperature domain after ageing. The increase in $\mathrm{G}^{*}$ after PAV ageing is understandably greater than after RTFOT ageing due to the prolonged ageing process in the PAV. An increased complex modulus is observed for the aged PMB as compared with the original one.

It is also noticed that the increase in temperature is followed by a decrease in the complex modulus; this is observed for aged and unaged binders. Lower slope of complex modulus means that the asphalt is softer, also higher complex modulus have benefit since it reduce rutting problems in the asphalt. This phe- 
nomenon is identical to that seen for the base bitumen and confirms the hypothesis that the increase in $G^{*}$ is attributed solely to the oxidative ageing of the base bitumen in the PMB and that the bitumen phase in the PMB is aged in a similar to that of an unmodified bitumen.

The main curve of the phase angle for base bitumen and modified bitumen, against temperature was obtained, as illustrated in figures $2 \mathrm{a}$ and $2 \mathrm{p}$.

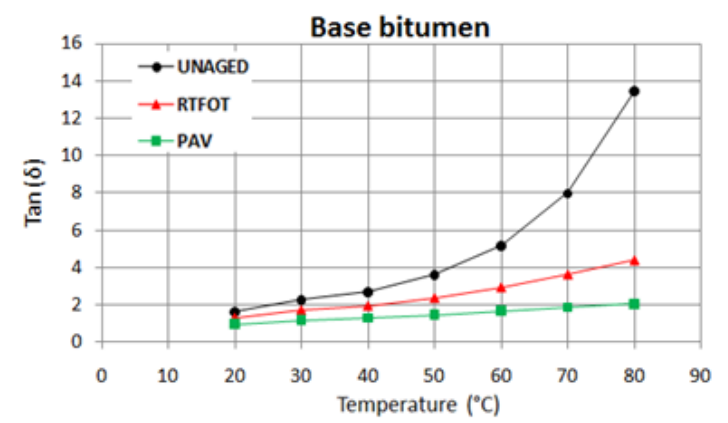

(a)

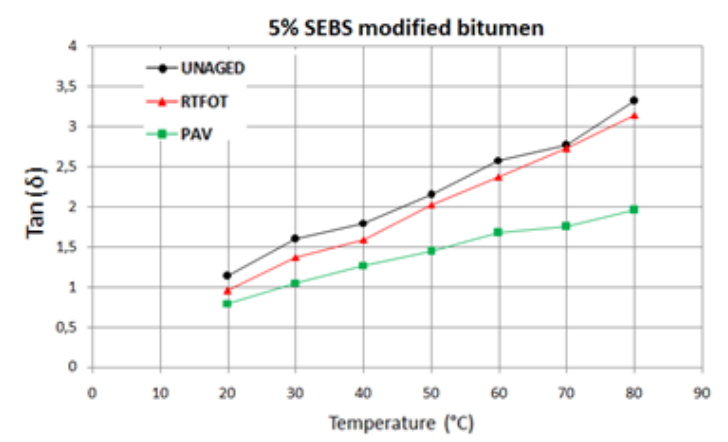

(b)

Fig. 2. Phase angle as function of temperature at $10 \mathrm{rad} \mathrm{s}^{-1}$ for:(a) Base bitumen, (b) $5 \%$ modified bitumen before and after ageing.

Figures $2 \mathrm{a}$ and $2 \mathrm{p}$ reveals changes in the viscoelastic properties of the binders during ageing. As can be seen, the elasticity of the base bitumen and modified binders is increased by ageing, as indicated by a decrease in phase angles in the temperature range. Owing to ageing, the recorded decrease in phase angles suggests that a variation from a more viscous to more elastic behavior occurs.

The decrease in phase angles for the base bitumen and the modified bitumen binder was more pronounced after PAV test compared to RTFOT test. For the base and 5\% SEBS modified bitumens, complex modulus is increased and phase angle is reduced through ageing.

The results obtained indicate that the aged SEBS modified bitumen display better rheological properties than the corresponding base bitumen. In practice, this should be favorable for longterm durability of asphalt pavements.

\subsubsection{Ageing index properties of the modified bitumen}

Values of ageing index for the base and SEBS modified binders are represented in figures $3 \mathrm{a}$ and 3 b for complex modulus and phase angle respectively.

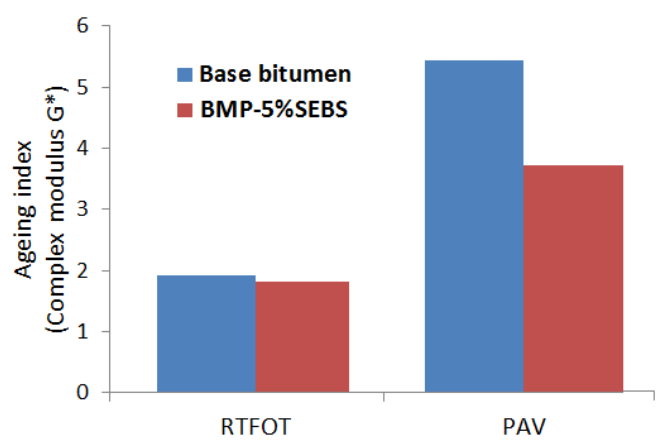

(a) Ageing index for complex modulus of base bitumen and $5 \%$ SEBS modified bitumen.

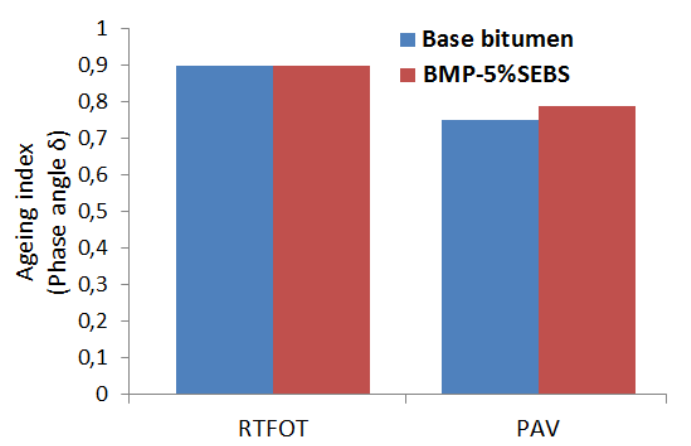

(b) Ageing index for phase angle of base bitumen and 5\% SEBS modified bitumen.

Fig. 3. Ageing index of base bitumen and 5\% SEBS modified bitumen for (a) complex modulus, (b) phase angle

In figures $3 \mathrm{a}$ and $3 \mathrm{~b}$, the ageing index for the SEBS modified bitumen are similar to those seen for the paving grade bitumens, although there is a tendency for them to be slightly lower, particularly after PAV ageing, indicating a superior resistance to age-hardening.

In addition, the ageing index of complex modulus (fig. 3 a) is observed to be greater than 1 in all testing temperatures, which indicates hardening of these binders during RTFOT and PAV test.

Moreover, the results indicate that the ageing index after PAV are lower for the modified bitumen binder compared to the base bitumen, which indicates that the modification process leading to a reduced influence of the degree of bitumen hardening.

However, the values of the ageing index are approximately similar for the base and modified bitumen binder after RTFOT.

\subsubsection{Rheological black diagrams}

The changes in the rheological characteristics of the base and $5 \%$ SEBS modified bitumen after ageing are shown in the form of black diagrams in figures $4 \mathrm{a}$ and $4 \mathrm{p}$ respectively.

The black diagram, in figures $4 \mathrm{a}$ and $4 \mathrm{p}$, show a continuous shift of the curves towards lower phase angles after ageing. The shift in the Black diagram curves is caused by dual actions of an increase in complex modulus, indicating the hardening of the bitumen, and a decrease in phase angle, indicating an increase in the elastic behaviour of the bitumen. In addition, the black diagram of the 5\% SEBS modified bitumen shows a continu- 


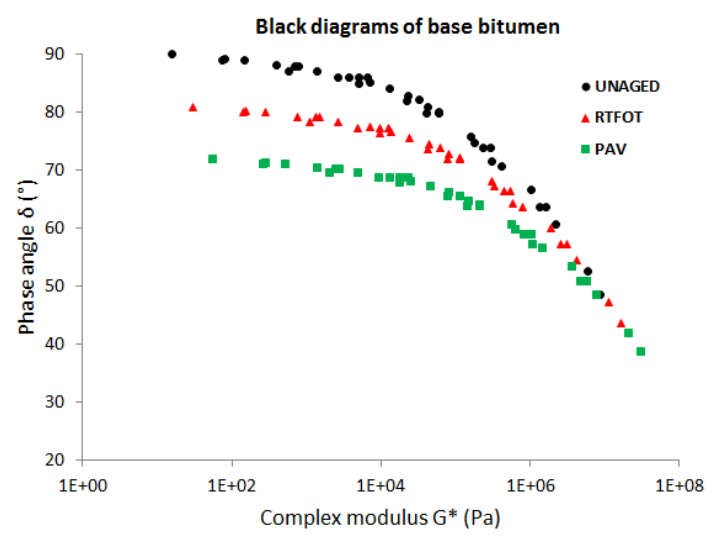

(a)

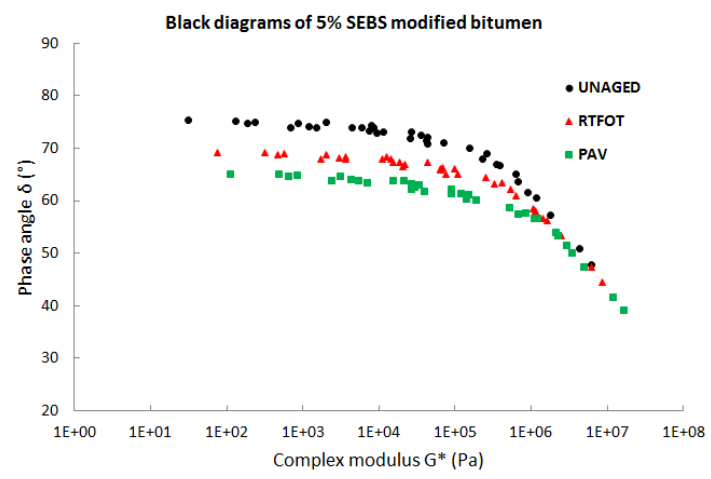

(b)

Fig. 4. Black diagrams for: (a) the base and (b) the modified bitumen before and after ageing

ous shift of the curves towards lower phase angles after ageing similar to that seen for penetration grade bitumens.

\subsubsection{Cole-Cole diagrams}

The Cole-Cole diagram for the unaged and aged base bitumen is shown in figure $5 \mathrm{a}$. The diagram gives an indication of the viscoelastic balance of the bitumen without requiring temperature and/or frequency as one of the axes. Although, at a particular temperature and loading frequency, the viscoelastic balance of the bitumen after ageing becomes more elastic and less viscous, with the bitumen having a larger increase in storage modulus than loss modulus, the time-temperature equivalency of the bitumen means that the unaged and aged Cole-Cole diagrams overlap. This is seen in figure 5 a, where the Cole-Cole plots for the aged bitumen have simply shifted along the sale line towards the upper right hand corner of the diagram and towards a more elastic stiffer rheological behavior.

The Cole-Cole diagram for the unaged and aged modified bitumen, in figure $5 \mathrm{~b}$, also illustrates that the effect of ageing differs in two region dominated by the bitumen phase and the polymer phase. The rheological behaviour at G' values greater than $10^{4} \mathrm{~Pa}$ is similar to that seen for the unmodified bitumens. In this region the effect of ageing is simply to shift the Cole-Cole plot towards the upper right hand corner of the diagram and, therefore; towards a more elastic, stiffer rheological behaviour.

The rheological behavior at G' values below $10^{4} \mathrm{~Pa}$ shows a

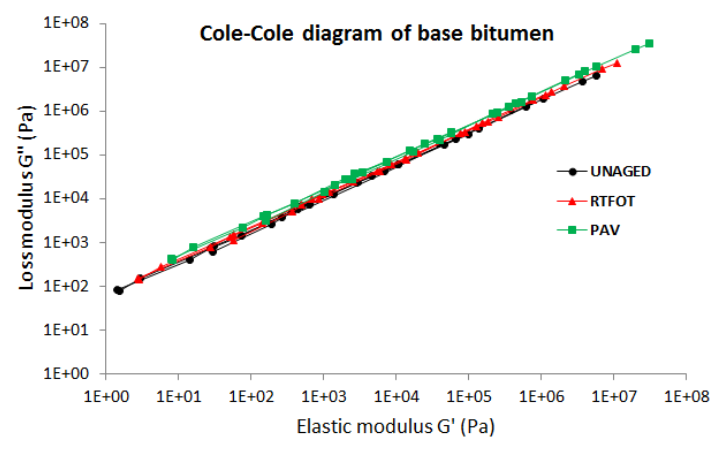

(a)

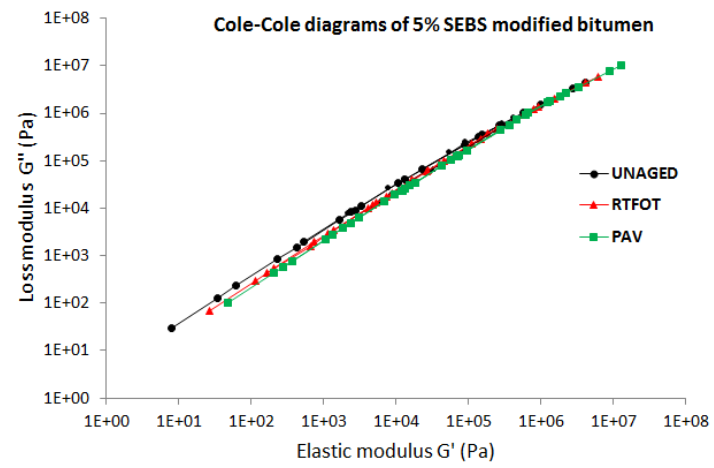

(b)

Fig. 5. Cole-Cole diagrams for: (a) the base and (b) the modified bitumen before and after ageing

shifting of the plot towards a more viscous fluid-like behavior after ageing.

\subsubsection{Storage and loss modulus isochronal plots}

After ageing both unmodified bitumen and SEBS bitumen modified show an increase in the storage shear modulus $G^{\prime}$ and in the loss shear modulus G', as shown in figures 6 and 7 respectively. The increase for all these parameters was more pronounced after PAV test compare to RTFOT test.

The lower complex modulus is mainly due to a decrease of both the elastic G' and the viscous G' component as shown in the figures 6 and 7

The higher complex modulus is mainly due to an increase of both the elastic G' and the viscous G" components, but the increase in the elastic component was more considerable compare to a slight increase in the viscous component. Therefore the elastic component $G$ ' seems to be more affected by the ageing as compared to the viscous component G'.

Since phase angle is a measure of the ratio between loss modulus and storage modulus Tang $(\delta)=\mathrm{G}$ " $/ \mathrm{G}$ ', the decreased phase angle implies that ageing leads to a greater increased in both elastic component $G^{\prime}$ and in viscous component $G$ " this can happen only if the increase in $G^{\prime}$ is greater than increase in G”.

Owing to ageing, the recorded decrease in Tang $(\delta)$ suggests that a variation from a more viscous to more elastic behavior occurs.

The results indicate that in all cases (unmodified and modi- 


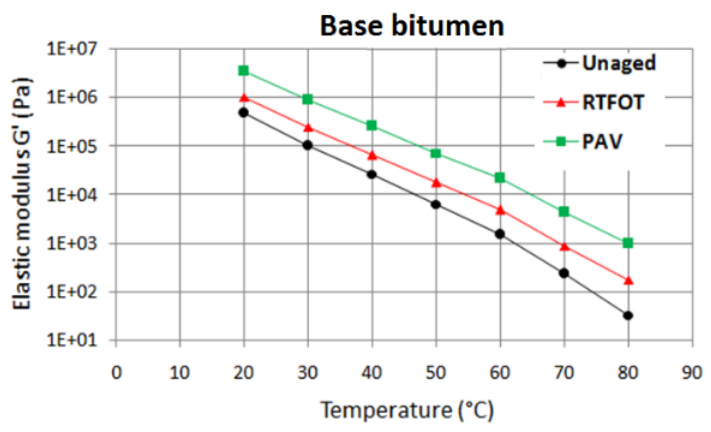

(a)

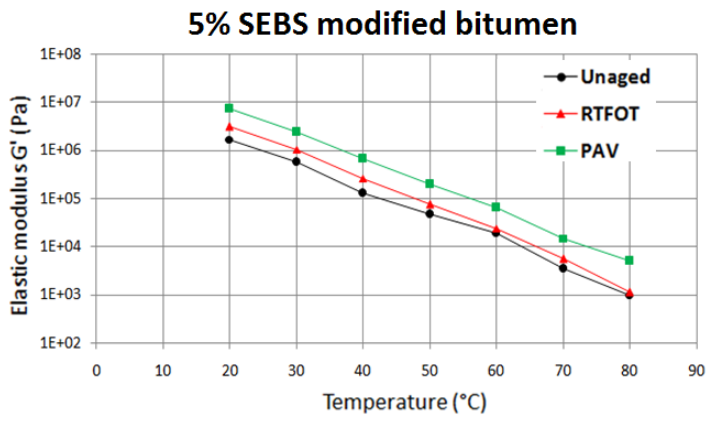

(b)

Fig. 6. Elastic modulus as function of temperature at $10 \mathrm{rad} \mathrm{s}^{-1}$ for: (a) the base and (b) the modified bitumen before and after ageing.

fied bitumen) the increase in the elastic component $\mathrm{G}^{\text {' is more }}$ predominant than the viscous component G'. The high value of $\mathrm{G}^{\prime}$ is an advantage since it will improve further the rutting resistance during service. Since the loss shear modulus remains relatively high, thus the resistance to fatigue cracking during service will remain relatively high and also because viscoelastic energy dissipation can still take place to relieve fatigue-cracking stresses.

\section{Conclusions}

The application of SEBS-modified bitumen have reported many advantages; for instance improved bitumen resistance to rutting, high softening point, reduction in road pavement maintenance cost, lower fatigue cracking and less temperature susceptibility.

Considering the results obtained by DSR test, it is seen SEBS PMBs binder exhibits increases complex modulus $\left(\mathrm{G}^{*}\right)$ and has more decreased phase angle values, consequently, using the SEBS polymer is considerably improves the elastic properties and rutting resistance of bitumen.

The properties of modified bitumen are largely influenced by the process of ageing. After thermo-oxidation aging, both unmodified and modified samples become harder, being more pronounced for the base bitumen samples and those modified with SEBS.

The ageing mechanisms for the SEBS modified bitumen as measured by the changes in their rheological characteristics after ageing; were found to differ considerable from that found for base bitumen. As a result of the rheological changes, the me-

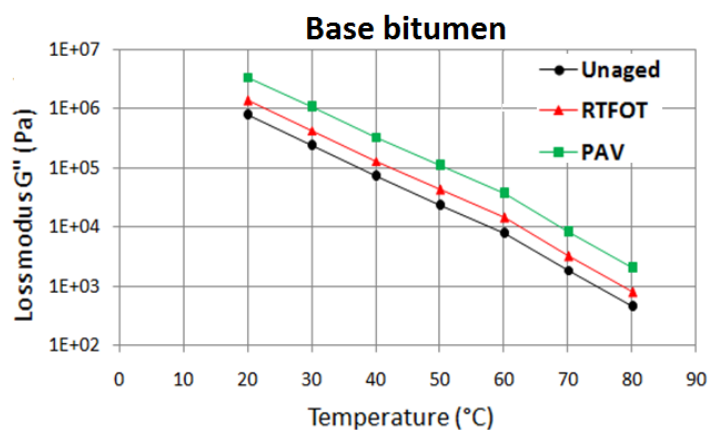

(a)

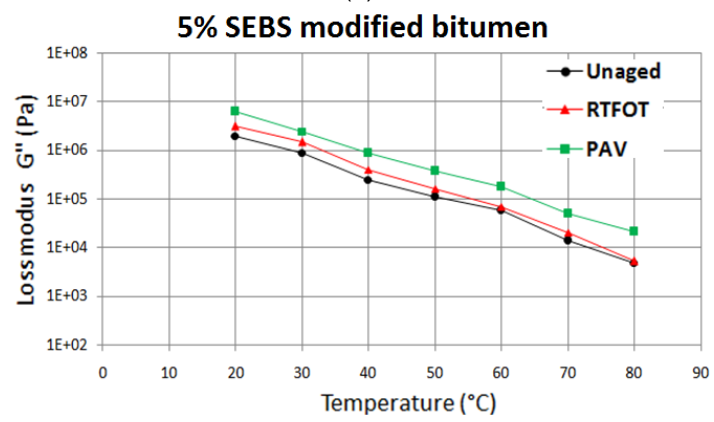

(b)

Fig. 7. Loss modulus as function of temperature at $10 \mathrm{rad} \mathrm{s}^{-1}$ for: (a) the base and (b) the modified bitumen before and after ageing.

chanical properties of aged SEBS modified binders improved, as indicated by increased complex modulus and decreased phase angle.

The aged modified samples are characterized by higher stiffness and elasticity, due to an increase of elastic modulus G'. The high value of $\mathrm{G}^{\prime}$ is an advantage since it will improve further the rutting resistance during service. Since the loss shear modulus remains relatively high, thus the resistance to fatigue cracking during service will remain relatively high also because viscoelastic energy dissipation can still takes place to relieve fatigue-cracking stresses.

The results obtained indicate that the aged SEBS-modified bitumen display better rheological properties than the corresponding base bitumen. In practice, this should be favorable for longterm durability of asphalt pavement

\section{References}

1 Lu X, Isacsson $\mathbf{U}$, Effect of ageing on bitumen chemistry and rheology, Construction and Building Materials, 16(1), (2002), 15-22, DOI 10.1016/S09500618(01)00033-2

2 Sibachir D, Dekhli S, Ait mokhtar K, Rheological properties and storage stability of SEBS polymer modified bitumen, International Journal of Engineering Science \& Technology, 5(5), (2013), 1031-1038.

3 Whiteoak D, Read JM, The Shell Bitumen Handbook, Thomas Telford Services Ltd; London, 1999.

4 Roberts FI, Kandhal PS, Brown E R, Lee D, Kennedy TW, Hot mix asphalt materials, mixture design and construction, NAPA Research and Education Foundation; USA, 1996.

5 Bahia HU, Anderson DA, Strategic highway research program binder rheological parameters: background and comparison with conventional properties, Transportation research board, 1488, (1995), 32-39. 
6 Airey GD, Rheological properties of styrene butadiene styrene polymer modified road bitumen, Fuel, 82(14), (2003), 1709-1719, DOI 10.1016/S00162361(03)00146-7

7 Petersen J, Chemical composition of asphalt as related to asphalt durability, Transportation research board, 999, (1984), 13-30.

8 Branthaver $\mathbf{J}$, Petersen $\mathbf{J}$, Binder characterization and evaluation, National Research Council, 1994, http://onlinepubs.trb.org... nepubs/shrp/SHRP-A-368.pdf

9 Lu X, Isacsson U, Chemical and rheological evaluation of ageing properties of SBS polymer modified bitumens, Fuel, 77(9-10), (1998), 961-972, DOI 10.1016/S0016-2361(97)00283-4

10 Sengoz B, Isikyakar G, Evaluation of the properties and microstructure of SBS and EVA polymer modified bitumen, Construction and Building Materials, 22(9), (2008), 1897-1905, DOI 10.1016/j.conbuildmat.2007.07.013

11 Sengoz B, Topal A, Isikyakar G, Morphology and image analysis of polymer modified bitumens, Construction and Building Materials, 23(5), (2009), 1986-1992, DOI 10.1016/j.conbuildmat.2008.08.020 